\author{
Military Technical College \\ Kobry El-Kobbah, \\ Cairo, Egypt.
}

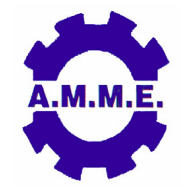

\title{
CONGESTION DUE TO TRAFFIC DESIGN AND ITS IMPACT ON FUEL CONSUMPTION AND VEHICLE EMISSIONS: A CASE STUDY
}

\author{
A. A. Abdel-Rehim*
}

\begin{abstract}
With the fast-growing economy and population, transportation has become a crucial component of modern life in Egypt. Sales of road vehicles have been growing at a tremendous speed over the last few years. On the other hand, the growth of infrastructure is however much slower than that of vehicles. This has led to severe congestion problems in the city of Cairo evidenced by very low average vehicle speeds and high percentages of driving time in idling, acceleration and deceleration.
\end{abstract}

Traffic congestion has a direct impact on quality of life in most of countries. Congestion deals with much more than just the cost of burning fuel, wasting time and car maintenance but it affects drivers attitude, health and work performance. It is also leading to more crashes, and air pollution. Congestion is ultimately resulting in a less productive economy and reduced quality of life for many people. Of course there are solutions which could reduce the effect of congestions on the people's life and the country economy in Egypt.

In the present paper facts about the cost of congestions in one of the many congestion spots around Cairo are presented. In the present case study the congestion is resulted from adopting one of the traffic designs in an improper place (U-turn concept). Fuel consumption, wasted time, traveled distance, are some examples of the estimated parameters due to the congestion in $9 \mathrm{U}$-Turns which were chosen in one of the main streets in Cairo.

\section{KEY WORDS}

U-Turn, Traffic design, Congestion, Fuel consumption, Engine emissions.

\footnotetext{
* Mechanical Engineering Dept., The British University in Egypt (BUE), El-Shrouk City, Egypt. On leave from Shoubra Faculty of Engineering, Benha University, Cairo, Egypt.
} 


\section{INTRODUCTION}

Population growth and increased urbanisation and industrialisation are accelerating the use of motor vehicles all over the world. In Egypt sales of road vehicles and cars have been growing at a tremendous speed over the last few years, figure (1). The monthly AMIC (Egyptian Automotive Marketing Information Council) report showed that the road vehicle population in Egypt grew by a percentage of $17.4 \%$ (from 205521 vehicles in 2009 compared to 248917 vehicles in 2010) [1]. Most vehicles, especially private-owned ones, are concentrated in major cities such as Great Cairo and Alexandria.

The growth of number of vehicles on the Egyptian's roads on the average of 21,000 vehicles a month has led to sever traffic congestion problems especially in the city of Cairo. Congestion is nothing new; it has been existed in cities for centuries [2].

The effect of traffic congestions on the quality of life can be measured from different points which include but not limited to;

- Increasing the accident rates.

- Affecting the economy due to increasing the rate of fuel consumption and vehicle maintenance and also shipping cost.

- Increasing the rate of exhaust emissions.

- Wasting time.

- Increasing aggressive driving which leads to frustration and stress.

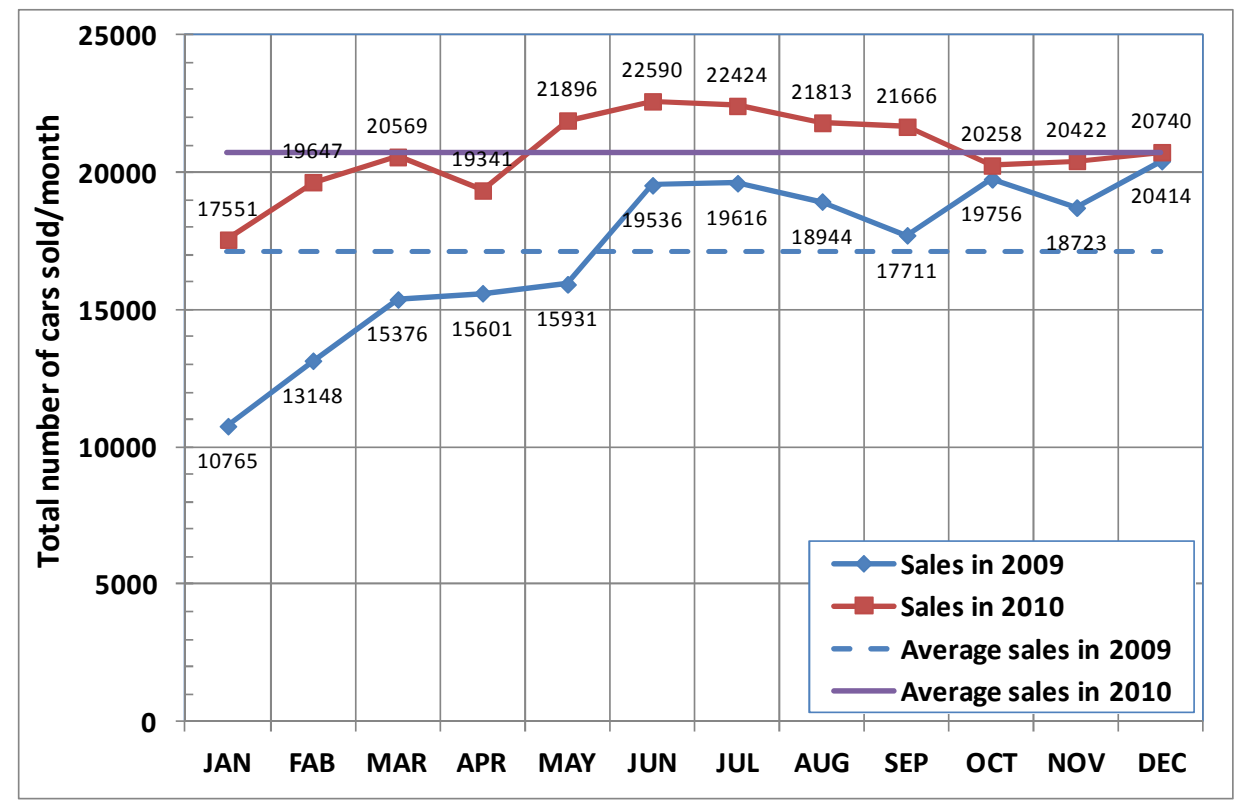

Figure (1) Comparison of total number of cars sold monthly in Egypt in 2009 and 2010.

\section{Impact of Congestions on Fuel Consumption}

There are many factors can affect the fuel consumption of any vehicle, including: driving style and driver behavior, vehicle acceleration, braking and driving speed, overall age and different technologies installed in the vehicle, weather, road 
conditions, and vehicle operating conditions. Variations in vehicle fuel consumption and emission rates due to congestions are usually associated with changes in cruise speeds, driver acceleration aggressiveness, road grade and time spent on idling speed [3-5]. All these factors can be grouped into two broad categories; (i) technical factors relating to the design and engineering of the vehicle; (ii) operational factors relating to the way in which the vehicle is used.

A driving pattern which experience fluctuating speeds or stop-and-go which characterize congestions is generally associated by an increase in fuel consumption. The results obtained by many researchers showed that vehicle fuel consumption and emission rates per unit distance are optimum in the range of 60 to $80 \mathrm{~km} / \mathrm{hr}$ [6-8]. The findings offered in [8] showed that a decrease in a facility speed limit from 72 to $56 \mathrm{~km} / \mathrm{h}$ results in an increase of $15 \%$ in the vehicle fuel-consumption rate.

It was presented in [9] that for the average vehicle with a 3-litre engine, every 10 minutes of idling costs 300 milliliters in wasted fuel, and one half of a liter if the vehicle has a 5 -litre engine.

\section{Impact of Congestions on Pollution}

Vehicular emissions were found to be major sources of air pollution in many cities around the world [10], where the major four pollutants related to vehicles are carbon monoxide (CO), nitrogen oxides (NOx), unburned hydrocarbons $(\mathrm{HC})$ and particulate matter (PM) [7]. Traffic congestions have been indicated by different researchers as a major factor in road traffic emissions and air quality degradation [11, 12].

Similar to fuel consumption it was observed that idling or low-speed travel and more frequent acceleration result in higher emissions compared to steady and moderate speeds $[8,13]$.

It was presented in [6] that increasing average arterial speeds from 16 to $32 \mathrm{~km} / \mathrm{h}$ reduces $\mathrm{HC}$ and $\mathrm{NO}_{x}$ emissions by roughly 40 and 20 percents respectively. A study in Atlanta estimated that coordinating traffic signals along an arterial which modifies the average speed, the acceleration and deceleration needs, and idling speed, would result in a reduction in emissions of nine percent [14].

\section{Impact of Congestions on Driver's Behavior}

Increasing fuel consumption, air pollution and car maintenance are not the only factors connected to traffic congestions, but drivers are also suffering from undesirable psychological and physiological responses as a result of driving much more time in such environment. Drivers who are experiencing daily congestions are facing more elevated blood pressure, increased negative mood states, lowered tolerance for frustration, increased irritability, increased levels of stress and aggression, and more impatient driving behavior especially if they are late or the congestion is unpredictable [15, 16]. According to the analysis offered in [17], commuting may be one of the most stressful experiences of urban life. Lowered job satisfaction, higher illness rates, absenteeism and lower performance on various cognitive tasks have also been found to be related to longer or more difficult 
commutes. Different researches have addressed also the problems of aggressive behavior of driving and traffic crashes [18, 19].

Based on the survey conducted in [17] on drivers facing every day congestions, 44\% of them experienced an increase in their stress levels, $25 \%$ of respondents report feelings of increased anger, $16 \%$ reported a negative effect on their work or school performance and $11 \%$ reported a less sleep time.

\section{THE PROBLEM}

Today, there are many different traffic designs such as traffic signals, U-turns, roundabouts $[20,21]$. As the traffic demand approaches and/or exceeds the capacity of the roads, congestions occur. Traffic demands vary significantly with the change of the season of the year, the day of the week, the time of the day, the weather, work zones, and traffic incidents. A good traffic design reduces the travel distance, the total journey time (including idle time), fuel consumption, and exhaust emissions, etc. A bad traffic design creates traffic congestions which result in more aggressive driving, and negatively affects the fuel economy, air pollution, and the total vehicle performance.

U-Turn as a traffic design concept is a good solution to ensure traffic flow and avoid jams on many roads and streets. The Median U-turn design was used for the first time by the Michigan Department of Transportation at the intersection of 8 Mile Road (M-102) and Livernois Avenue in Detroit in the early 1960s to reduce traffic accidents and congestions at intersections [22], figure (2).

Median U-turn design entails lower construction and right-of-way costs than many conventional options and improves safety by eliminating left turns at the intersection. To turn left, vehicles must drive few hundred meters past the intersection and cross the median in a signal-regulated U-turn lane, from which they can safely re-enter traffic and make a right turn onto the side street.

This type of intersection configuration, as with any engineered solution to a traffic problem, carries with it certain advantages and disadvantages and has been subject to several studies [22-24]. Studies have shown a major reduction in left-turn collisions and a minor reduction in merging and diverging collisions, due to the shifting of left turns outside the main intersection. In addition, it reduces the number of different traffic light phases, significantly increasing traffic flow. Since separate phases are no longer needed for left turns, this increases green time for through traffic. Consequently, the timing of traffic signals along a highway featuring the design is made easier by the elimination of left-turn phases both on that highway and along intersecting roadways contributing to the reduction of travel times and the increased capacity of those roadways. Finally it has been shown to enhance safety to pedestrians crossing either street at an intersection featuring the design, since they only encounter through traffic and vehicles making right turns.

But to utilize the previous advantages of this design, different parameters have to be considered such as road type, road size, location, flow capacity, beside the right choice for the U-turn configuration [22]. 


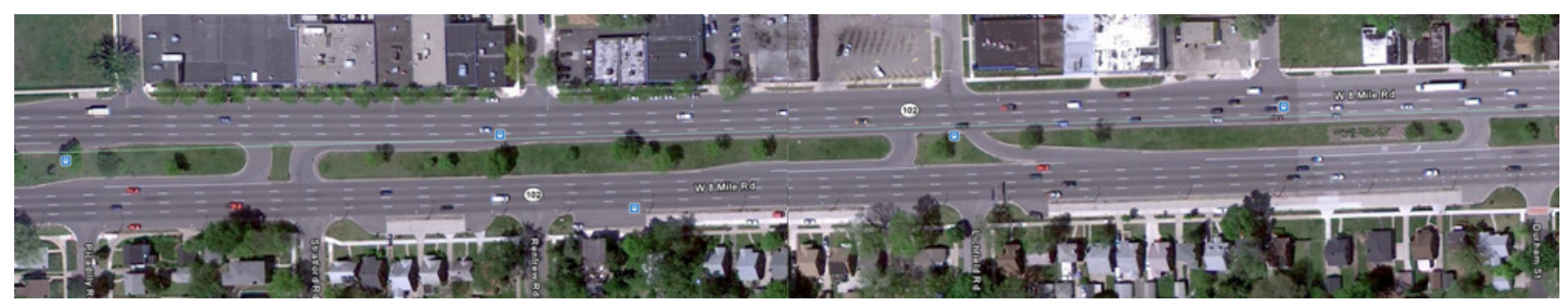

Figure (2) A typical Michigan left layout; Telegraph Road (U.S. Highway 24), Michigan.

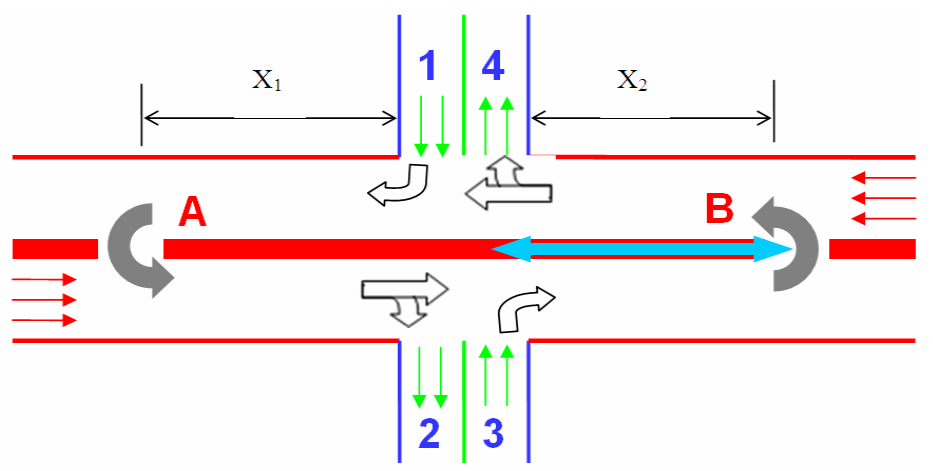

Figure (3) Schematic diagram for the concept of U-Turn traffic design.

The purpose of using U-turns in Egypt is a little bit shifted from the original Michigan left turn one. Figure (3) presents a schematic diagram for the concept of U-Turn traffic design, where for a vehicle to move from point (1) to point (2) it has to merge in the traffic on the right side and then turn back through u-turn (A) towards point (2). This route will increase the total traveling distance by simply a value of $2 X_{1}$ as shown in the figure. The distance will increase more if the vehicle moved from point 1 and returned back to point (4) where the total traveling distance will increase by $2 X_{1+}$ $2 \mathrm{X}_{2}$.

The case is not limited to increasing the traveling distance, but it causes traffic congestions due to the merger between the two flows. This causes a reduction in vehicle's speeds and increases the total traveling time and consequently the rate of fuel consumption and exhaust emissions.

Unfortunately, this concept was adopted recently in Egypt for most of the main and minor roads in Cairo where the controlled intersections were eliminated. Because of using this uncontrolled design to control intersections, many of congestion spots are generated all over the city due to the limited capacity of the roads which were loaded by an extra number of vehicles trying to move from one road to another with lot of chaos, figure (4). The turning for heavy and bigger vehicles becomes a problem causing more unexpected delay.

U-Turns can replace standard intersections at places with very low density and very less space which is not the case in the present case study. 


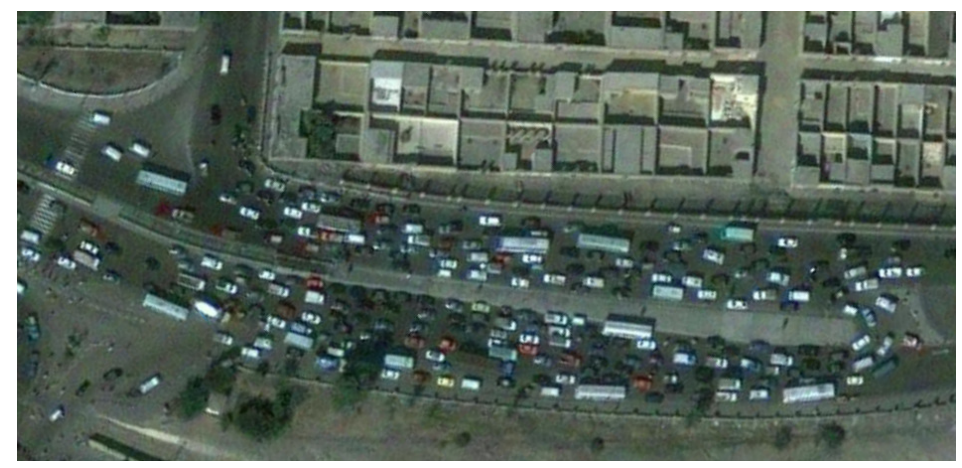

Figure (4) A satellite image for one of the U-turns on Nasr road, Cairo.

\section{CASE STUDY ANALYSIS}

\section{Introduction}

It would be difficult to measure the engine fuel consumption for all car brands running on road by driving them. It would also be almost impossible to include all variables impacting the vehicle in labs. Instead, there are two acceptable methods to test vehicles:

1. By using a carefully controlled laboratory testing method, where all vehicles are tested under identical conditions by simulating the real traveling route and that the results are consistent and repeatable. However, no test can simulate all possible combinations of traffic conditions, climate, driving behaviors and vehicle maintenance as mentioned earlier.

2. By using specially designed simulation programs which have the ability to simulate different driving and road conditions. To use this method, a number of approximations and assumptions are needed. Table (1) lists some of these assumptions and considerations which are essential for the simulation.

Using simulation softwares were used in different studies to estimate both fuel consumption and exhaust emissions. A comparison between the on-road fuelconsumption and emission measurements and one of the simulation models (VTMicro) revealed that the simulation method is efficient for modeling steady-state vehicle fuel consumption and emission behavior [8].

\section{Test Site Description}

Nasr road is one of the major roads in Nasr city area. This road is considered as an artery in the middle of Cairo. Unfortunately it has many congestion spots. The main reason for that is the nine $U$-turns which are located on a segment of the road in a total distance of $2594 \mathrm{~m}$. There are ten intersections with Nasr road between these U-turns. Four intersections are for main roads with almost the same importance and width as Nasr road. Figure (5) shows these intersections and the distances between the U-turns. 
Table (1). Some assumptions and approximations which are required to use simulation packages.

\begin{tabular}{|l|l|}
\hline \multicolumn{1}{|c|}{ Assumptions } & \multicolumn{1}{c|}{ Reasons } \\
\hline $\begin{array}{l}\text { Choose only one vehicle } \\
\text { size to represent the mid } \\
\text { size private vehicles. }\end{array}$ & $\begin{array}{l}\text { There are different models of cars with different } \\
\text { engine capacities in the Egyptian market. According } \\
\text { to AMIC report 1600 cc vehicles represent the most } \\
\text { selling size in Egypt. }\end{array}$ \\
\hline $\begin{array}{l}\text { All cars are in the middle } \\
\text { age rage; not too old or too } \\
\text { new which are equipped } \\
\text { with average technologies. }\end{array}$ & $\begin{array}{l}\text { There are high variations in the ages of cars; some } \\
\text { are very old with very basic technologies, and some } \\
\text { technologies. }\end{array}$ \\
\hline $\begin{array}{l}\text { All cars use gasoline 92\% } \\
\text { octane. }\end{array}$ & $\begin{array}{l}\text { There are different gasoline octane numbers, 90, 92, } \\
\text { 95, 98, and there are other fuels such as natural gas } \\
\text { and diesel fuels. }\end{array}$ \\
\hline
\end{tabular}

\begin{tabular}{|c|c|c|c|c|c|}
\hline \multicolumn{3}{|c|}{ A direction } & \multicolumn{3}{c|}{ B Direction } \\
\hline From U-turn & To U-turn & Distance & From U-turn & To U-turn & Distance \\
\hline 1 & 3 & 766 & 8 & 6 & 398 \\
\hline 3 & 5 & 549 & 6 & 4 & 454 \\
\hline 5 & 7 & 400 & 4 & 2 & 802 \\
\hline 7 & 9 & 876 & & & \\
\hline
\end{tabular}
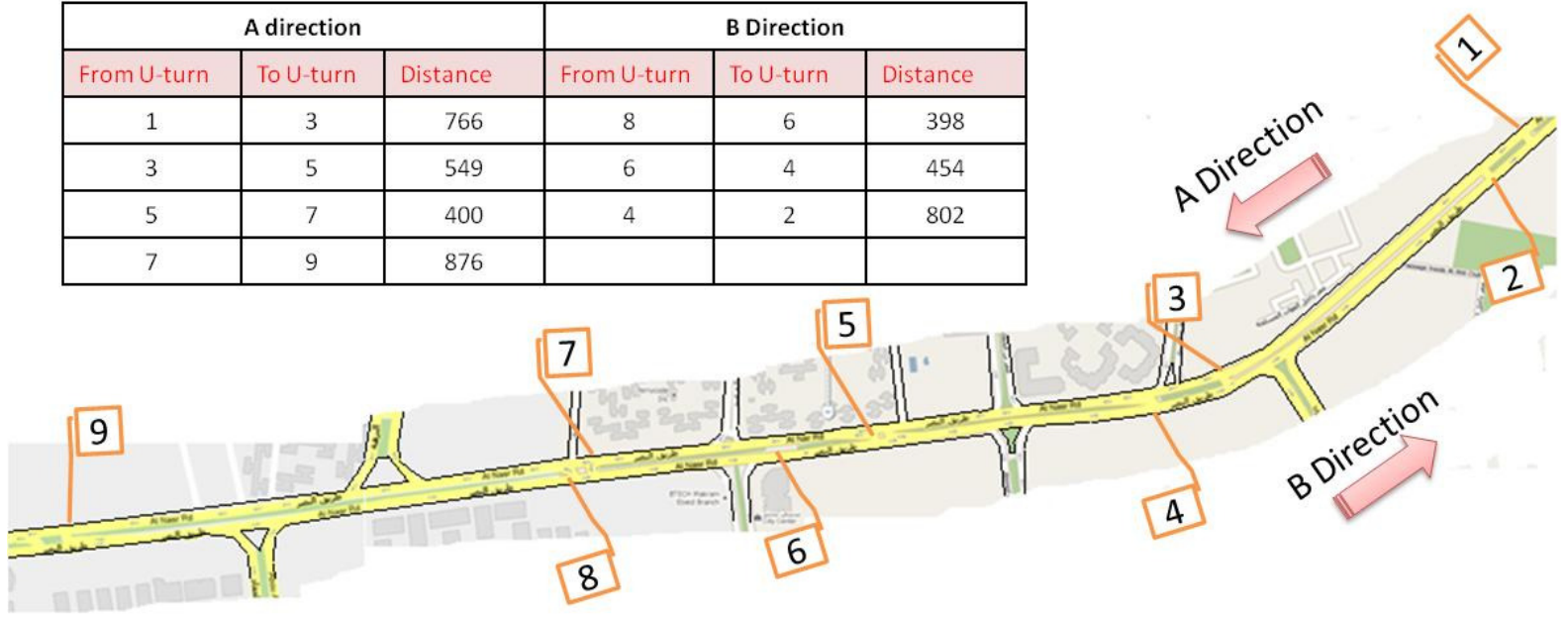

Figure (5) Total distances (in meters) between the main intersections on Nasr road and the corresponding U-turn.

\section{Traffic density on Nasr road at the U-turns}

Traffic density refers to the total number of vehicles making a U-turn at each location of the nine spots. There are two basic methods of traffic volume counts; manual and automatic [25]. In the present study, the manual method was adopted.

Since the traffic demands vary significantly with the time, four different days were chosen to represent the working days and the off days (Sat, Sun, Tus, and Fri). Six periods were chosen within each day to count the total number of vehicles passing each U-turn. However, the regular observation of traffic volumes over the years has identified certain characteristics showing that although traffic volume at a section of road varies from time to time, this variation is repetitive and rhythmic [25].

Figure (6) represents the average results obtained at each location and for the selected days in the week. As clearly seen in the figure, U-turns (1) and (8) carry the 

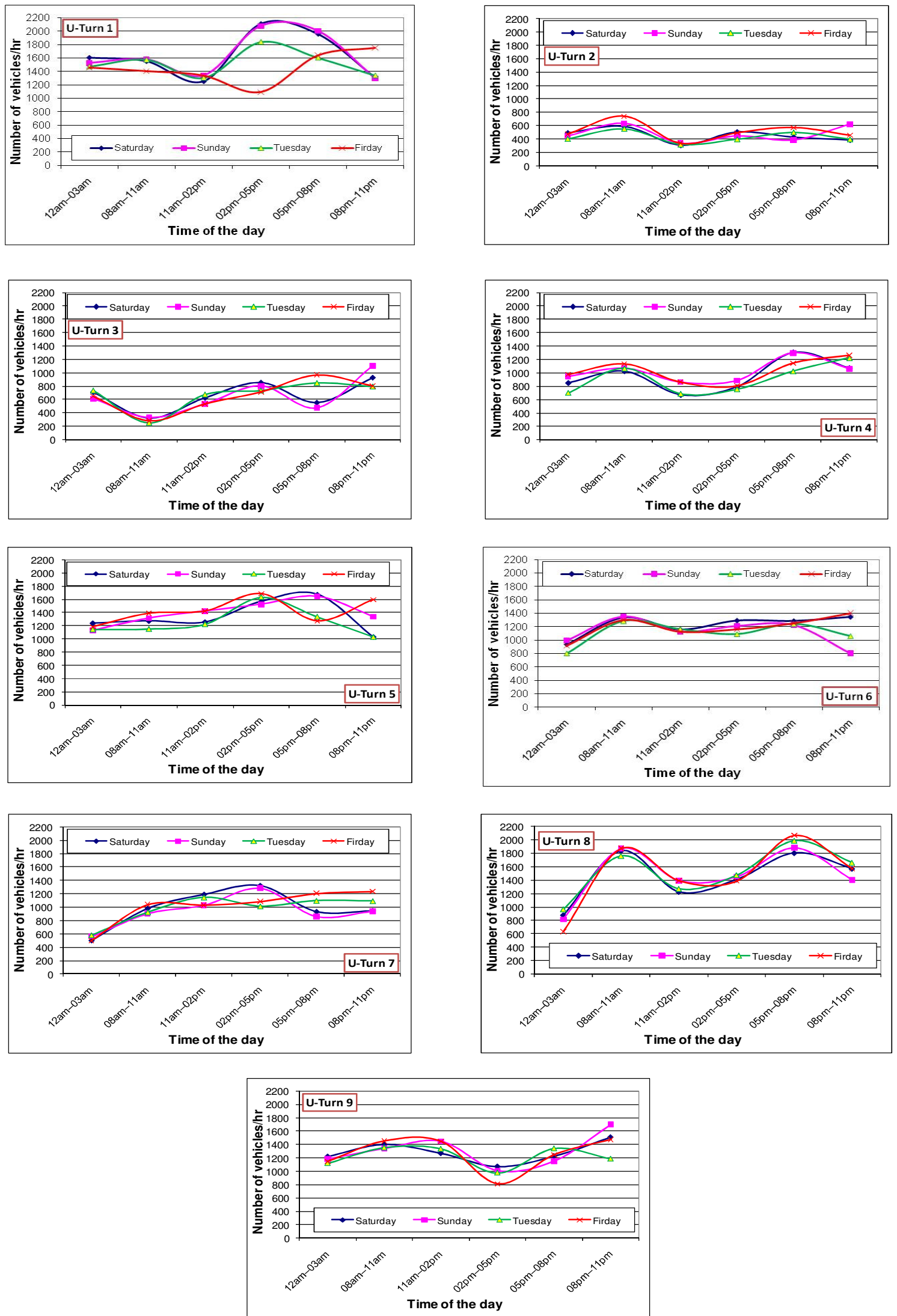

Figure (6) Number of vehicles at each U-turn and for the selected days. 
highest traffic and the afternoon time at about $5 \mathrm{pm}$ is the heaviest traffic time of the day. There is not much difference between the working days (Sun and Tus.) and the off days (Fri. and Sat.) in this point.

There are an average number of vehicles of about (466-1559) vehicle per hour crossing each $U$-turn to merge in the flow of the opposite direction as shown in figure (7). In this case the total traveling distance, time, fuel consumption, are increased due to two factors, one related to the extra distance and the other one is related to the resulted congestion.

\section{Measuring the Wasted Time and Extra Traveling Distances}

The extra traveling time and distance were measured for a sample between two roads, El-Nozha road and Abbas El-Aqad road, to involve the effect of U-turns 8 and 9 as shown in figure (8).

The above mentioned two roads are considered as major roads connected to ElNasr road. The flow coming from these roads has to merge to the flow in El-Nasr road to add a remarkable number of vehicles to the traffic. The extra traveling distance and time for two different routes are discussed in the following scenarios:-

I. For a vehicle to move from point $A$ to point $B$ on the other side of El-Nasr road, figure (8), it has to merge on the right side of El-Nasr road and travel for about $570 \mathrm{~m}$ to use U-turn 8 and then return back for about $570 \mathrm{~m}$ in the opposite direction to point $B$. In this journey, the vehicle has to spend about $277 \mathrm{sec}$ to travel an extra distance of about $1.2 \mathrm{~km}$. In the non congested time (light flow at midnight) this route can be covered in only $80 \mathrm{sec}$.

II. The case is worse if the route is to start from point $A$ to point $C$ through $U$-turns 8 and 9. The average time required to travel a distance of $1700 \mathrm{~m}$ is $364 \mathrm{sec}$ in this case. For light traffic this distance can be traveled in $120 \mathrm{sec}$. Figure (9) shows the accumulative time for the above routs.

\section{Measuring the Wasted Time and Extra Traveling Distances}

The extra traveling time and distance were measured for a sample between two roads, El-Nozha road and Abbas El-Aqad road, to involve the effect of U-turns 8 and 9 as shown in figure (8).

The above mentioned two roads are considered as major roads connected to ElNasr road. The flow coming from these roads has to merge to the flow in El-Nasr road to add a remarkable number of vehicles to the traffic. The extra traveling distance and time for two different routes are discussed in the following scenarios:-

- For a vehicle to move from point $A$ to point B on the other side of El-Nasr road, figure (8), it has to merge on the right side of El-Nasr road and travel for about $570 \mathrm{~m}$ to use U-turn 8 and then return back for about $570 \mathrm{~m}$ in the opposite direction to point $B$. In this journey, the vehicle has to spend about $277 \mathrm{sec}$ to travel an extra distance of about $1.2 \mathrm{~km}$. In the non congested time (light flow at midnight) this route can be covered in only $80 \mathrm{sec}$.

- The case is worse if the route is to start from point $A$ to point $C$ through $U$-turns 8 and 9 . The average time required to travel a distance of $1700 \mathrm{~m}$ is $364 \mathrm{sec}$ in this 


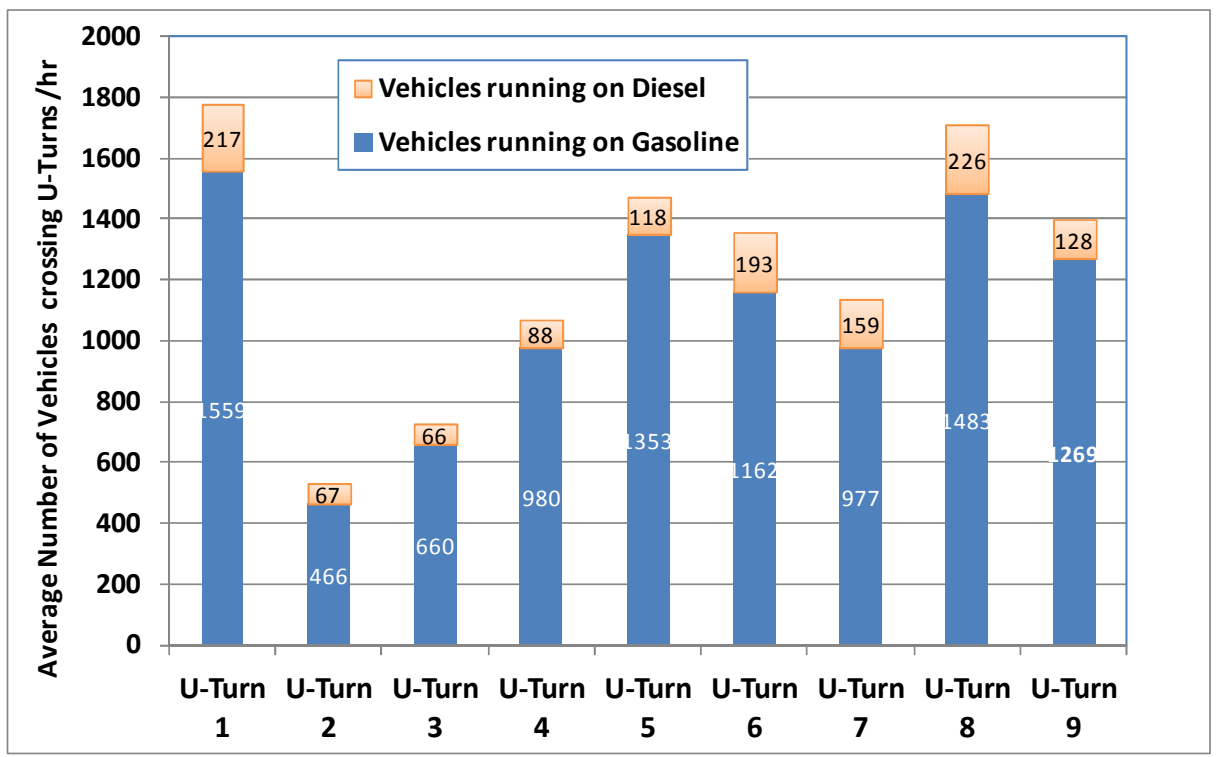

Figure (7) Average number of vehicles crossing each U-Turn over the whole week.

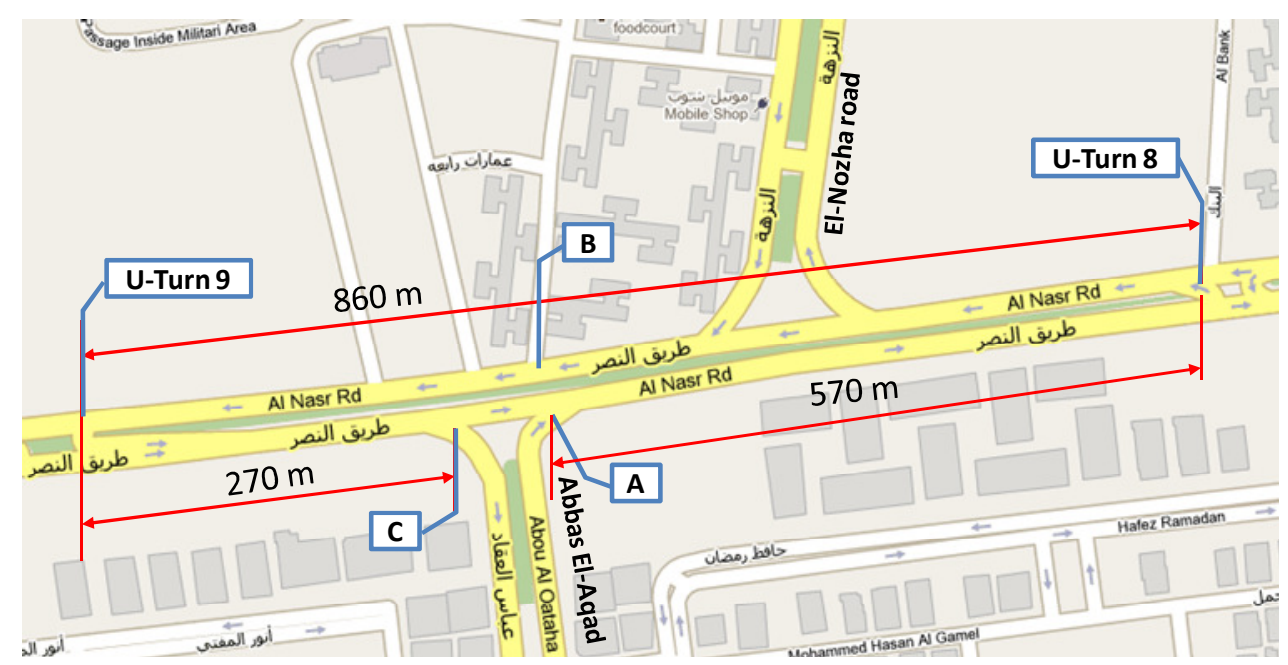

Figure (8) A map showing U-turns 8 and 9 on El-Nasr road and the main intersections (EINozha road, and Abbas El-Aqad road).

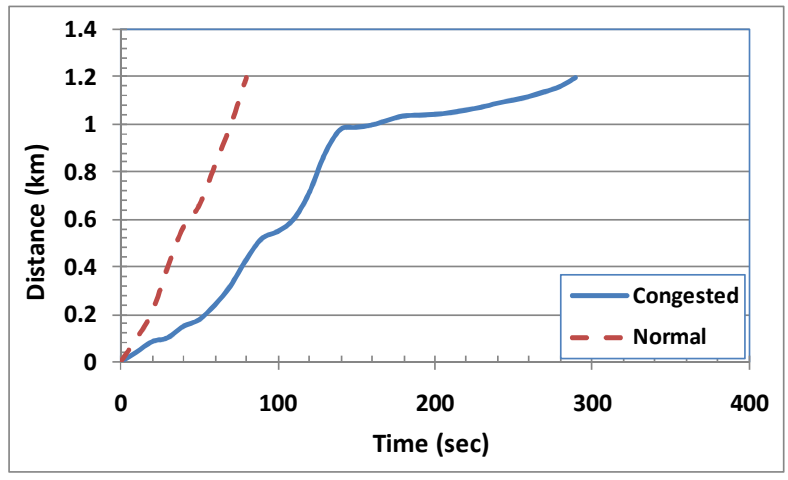

(a)

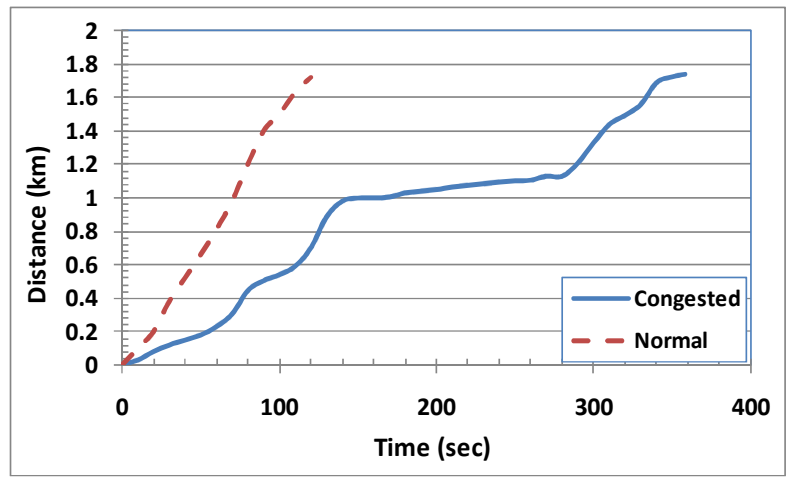

(b)

Figure (9) The required time to move from (a) point $A$ to point $B$ and (b) from point $A$ to point $C$ shown in figure (9). 
case. For light traffic this distance can be traveled in $120 \mathrm{sec}$. Figure (9) shows the accumulative time for the above routs.

\section{Estimating the Fuel Consumption, Exhaust Emissions and Operating Cost From a Sample U-Turn}

In the present study a commercial software package SIDRA [26] is used to estimate the operating cost, fuel consumption and pollutant emissions based on some essential information such as vehicle models, road designs, and some driver's related information. Evaluating intersections by estimating the above parameters are useful for planning and design evaluation purposes in traffic management.

The final output cost includes the direct vehicle cost from consuming a certain amount of fuel for a specific route and the indirect cost which includes (1) the consumables, repair and maintenance cost, and (2) the time cost for persons in vehicles. Table (2) shows some values used as key parameters in estimating the total cost in SIDRA software. The output results are presented in tables (3-6).

Table (2) Values for some key parameters used in estimating the total cost in SIDRA software.

\begin{tabular}{|c|c|c|}
\hline Parameter & Value & Notes \\
\hline Pump price of fuel (\$/liter) & $0.32 \$ /$ liter & $\begin{array}{l}\text { Fuel cost is estimated for } 2010 \\
\text { based on the national average } \\
\text { price for regular gasoline, } 92 \\
\text { Octane Number which is about } \\
\$ 0.32 / L \text { at the time of this study. }\end{array}$ \\
\hline Average income in $\$ / \mathrm{hr}$ & $3.3 \$ / h r$ & $\begin{array}{l}\text { Average income for full time } \\
\text { adult was estimated to be } \$ 500 \\
\text { per month. }\end{array}$ \\
\hline $\begin{array}{l}\text { Ratio of running cost to fuel } \\
\text { cost }\end{array}$ & 2.0 & \\
\hline $\begin{array}{l}\text { Average occupancy in persons } \\
\text { per vehicle }\end{array}$ & 1.5 persons & $\begin{array}{l}\text { Standered values used in } \\
\text { different countries showed an } \\
\text { average occupancy of } 1.5 \\
\text { persons [27]. }\end{array}$ \\
\hline $\begin{array}{l}\text { Light (private) vehicle mass } \\
\text { (average in } \mathrm{kg} \text { ) }\end{array}$ & $1400 \mathrm{~kg}$ & \\
\hline Vehicle size (majority in Egypt) & 1600 c.c. & $\begin{array}{l}\text { More than } 60 \% \text { of the private } \\
\text { owned vehicles in Egypt are } \\
1600 \text { c.c. }\end{array}$ \\
\hline $\begin{array}{l}\text { No. of wheels, tire diameter, } \\
\text { frontal area }\end{array}$ & $\begin{array}{c}4 \text { wheels, } 0.65 \\
\mathrm{~m}, 2.1 \mathrm{~m}^{2}\end{array}$ & \\
\hline Light vehicle idle fuel rate (L/h) & 1.35 & From the literature. \\
\hline
\end{tabular}




\section{Analysis and Discussion}

The existence of the U-turn affects the two flow directions on El-Nasr road. According to the total number of vehicles utilizing this road, there are 4678 vehicle per hour are affected by the intersection at U-turn 9 . The analysis presented in table (3) shows that according to the dimensions of this intersection and the road size, only 2096 vehicles could be handled in this intersection which results practically in an extra number of vehicles of about 2582 vehicles (123.2 \%) over the road capacity. The analysis shows also that the corresponding average delay in all directions (including the U-turn) is about $554 \mathrm{sec}$. (9.23 $\mathrm{min}$ ) which increases to $32.1 \mathrm{~min}$ in the worst lane.

The total number of vehicles crossing this intersection consumes about $1350.5 \mathrm{Lit} / \mathrm{hr}$ of fuel which costs $405.15 \$ / \mathrm{hr}$, while the total invoice costs about $1651.82 \$ / \mathrm{hr}$ when the time cost of persons and the required maintenance are included, table (3). Table (4) presents the output analysis over the whole year.

In the previous tables the main exhaust emissions are presented which include carbon dioxide, hydrocarbons, carbon monoxide, and nitric oxides. But since congestions result in aggressive driving attitude, noise pollution is another parameter which has to be considered. By measuring the noise level over 20 minutes period of time at one of the U-turns (No. 1) at two different times, heavy traffic time (5 pm) and light traffic time (after midnight), the results showed an increase in the average maximum decibels of about $14.1 \%$

Figure (10) and table (5) suggest one solution to reduce the cost by using controlled light signals at the intersection. As clearly seen in the table, the total cost is reduced by about $33.8 \%$ while the total fuel consumption is reduced by about $32 \%$. The enhancement in the total operating cost is reflecting the total enhancement in the traffic flow where as shown in table (5), the average delay time is reduced to 331.1 $\sec (5.51 \mathrm{~min})$.

More enhancements can be achieved if the U-turns mentioned in this study are controlled by light signals as offered in this analysis. Similarly, there are other designs which can help in controlling the traffic under such configurations and benefit both individuals and the government.

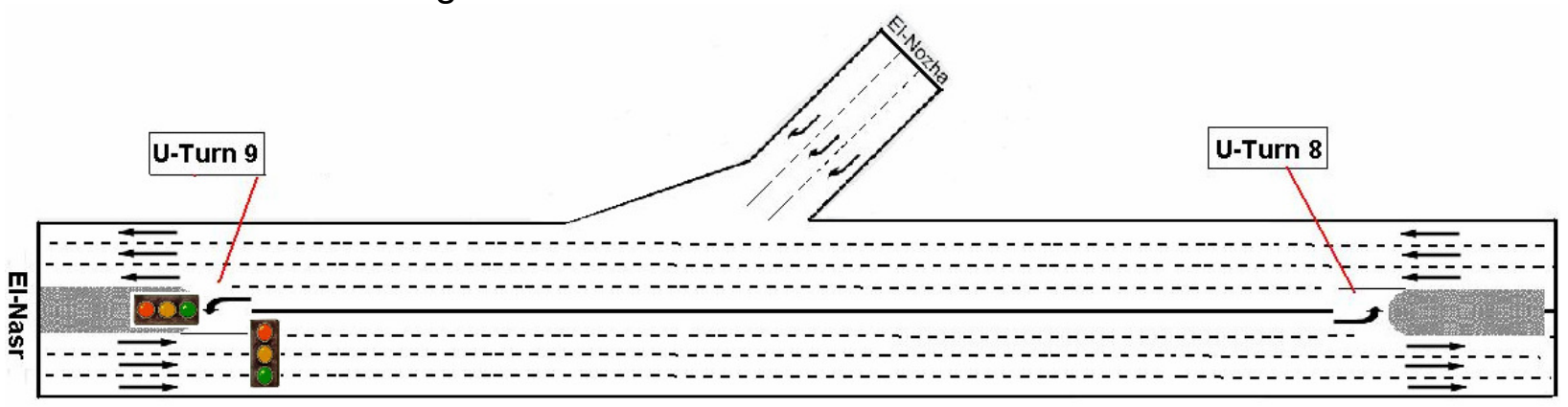

Figure (10) U-turn (9) with a suggested light signal to control the flow at the intersection. 
Table (3) Important Output results (hourly values) from SIDRA software for U-turn 9.

\begin{tabular}{|c|c|c|c|c|}
\hline \multirow{2}{*}{$\begin{array}{l}\text { Performance Measure } \\
\text { Demand Flows (Total) }\end{array}$} & \multicolumn{2}{|c|}{ Vehicles } & \multicolumn{2}{|c|}{ Persons } \\
\hline & 4678 & veh/h & 7017 & pers $/ \mathrm{h}$ \\
\hline Degree of Saturation & 2.232 & & & \\
\hline Practical Spare Capacity & -64.2 & $\%$ & & \\
\hline Effective Intersection Capacity & 2096 & veh/h & & \\
\hline Control Delay (Average) & 554.0 & $\mathrm{Sec}$ & 554.0 & $\mathrm{sec}$ \\
\hline Control Delay (Worst Lane) & 1925.6 & $\mathrm{Sec}$ & & \\
\hline $\begin{array}{l}\text { Control Delay (Worst } \\
\text { Movement) }\end{array}$ & 1925.6 & Sec & 1925.6 & sec \\
\hline Total Effective Stops & 61825 & veh/h & 92738 & pers $/ \mathrm{h}$ \\
\hline Effective Stop Rate & 13.22 & per veh & 13.22 & per pers \\
\hline Travel Distance (Total) & 3429.5 & veh-km/h & 5144.2 & pers-km/h \\
\hline Travel Distance (Average) & 733 & M & 733 & $\mathrm{~m}$ \\
\hline Travel Time (Total) & 835.9 & veh-h/h & 1253.9 & pers-h/h \\
\hline Travel Time (Average) & 643.3 & Sec & 643.3 & $\mathrm{sec}$ \\
\hline Travel Speed & 4.1 & $\mathrm{~km} / \mathrm{h}$ & 4.1 & $\mathrm{~km} / \mathrm{h}$ \\
\hline Cost (Total) & 1651.8 & $\$ / h$ & 1651.8 & $\$ / h$ \\
\hline Fuel Consumption (Total) & 1350.5 & L/h & & \\
\hline Carbon Dioxide (Total) & 3377.4 & $\mathrm{~kg} / \mathrm{h}$ & & \\
\hline Hydrocarbons (Total) & 7.369 & $\mathrm{~kg} / \mathrm{h}$ & & \\
\hline Carbon Monoxide (Total) & 95.49 & $\mathrm{~kg} / \mathrm{h}$ & & \\
\hline $\mathrm{NO}_{x}($ Total $)$ & 3.126 & $\mathrm{~kg} / \mathrm{h}$ & & \\
\hline
\end{tabular}

Table (4) Annual values based on table (3). Intersection (U-Turn 9) Performance - Annual values

\begin{tabular}{|l|cc|} 
Cost & 792,873 & $\$ / \mathrm{y}$ \\
\hline Fuel Consumption & 648,239 & $\mathrm{~L} / \mathrm{y}$ \\
\hline Carbon Dioxide & $1,621,128$ & $\mathrm{~kg} / \mathrm{y}$ \\
\hline Hydrocarbons & 3,537 & $\mathrm{~kg} / \mathrm{y}$ \\
\hline Carbon Monoxide & 45,835 & $\mathrm{~kg} / \mathrm{y}$ \\
\hline NOx & 1,501 & $\mathrm{~kg} / \mathrm{y}$ \\
\hline
\end{tabular}




\section{In case of using controlling light signals at the intersection}

Table (5) Important Output results (hourly values) from SIDRA software for U-turn 9.

\begin{tabular}{|c|c|c|c|c|}
\hline \multirow{2}{*}{$\begin{array}{l}\text { Performance Measure } \\
\text { Demand Flows (Total) }\end{array}$} & \multicolumn{2}{|c|}{ Vehicles } & \multicolumn{2}{|c|}{ Persons } \\
\hline & 4678 & veh/h & 7017 & pers/h \\
\hline Degree of Saturation & 2.137 & & & \\
\hline Practical Spare Capacity & -57.9 & $\%$ & & \\
\hline Effective Intersection Capacity & 2189 & veh/h & & \\
\hline Control Delay (Total) & 430.20 & veh-h/h & 645.30 & pers-h/h \\
\hline Control Delay (Average) & 331.1 & $\sec$ & 331.1 & $\mathrm{Sec}$ \\
\hline Control Delay (Worst Lane) & 1109.5 & sec & & \\
\hline Control Delay (Worst Movement) & 1109.5 & $\mathrm{sec}$ & 1109.5 & $\mathrm{Sec}$ \\
\hline Total Effective Stops & 7157 & veh/h & 10735 & pers/h \\
\hline Effective Stop Rate & 1.53 & per veh & 1.53 & per pers \\
\hline Travel Distance (Total) & 3429.5 & veh-km/h & 5144.2 & pers-km/h \\
\hline Travel Distance (Average) & 733 & $\mathrm{M}$ & 733 & M \\
\hline Travel Time (Total) & 546.4 & veh-h/h & 819.5 & pers-h/h \\
\hline Travel Time (Average) & 420.5 & $\mathrm{sec}$ & 420.5 & $\mathrm{Sec}$ \\
\hline Travel Speed & 6.3 & $\mathrm{~km} / \mathrm{h}$ & 6.3 & $\mathrm{~km} / \mathrm{h}$ \\
\hline Cost (Total) & 1093.7 & $\$ / h$ & 1093.6 & $\$ / h$ \\
\hline Fuel Consumption (Total) & 918.8 & $\mathrm{~L} / \mathrm{h}$ & & \\
\hline Carbon Dioxide (Total) & 2297.6 & $\mathrm{~kg} / \mathrm{h}$ & & \\
\hline Hydrocarbons (Total) & 4.841 & $\mathrm{~kg} / \mathrm{h}$ & & \\
\hline Carbon Monoxide (Total) & 62.52 & $\mathrm{~kg} / \mathrm{h}$ & & \\
\hline $\mathrm{NO}_{x}($ Total $)$ & 2.125 & $\mathrm{~kg} / \mathrm{h}$ & & \\
\hline
\end{tabular}

Table (6) Annual values based on table (5).

\begin{tabular}{|l|cc|}
\hline \multicolumn{3}{|l|}{ Intersection (U-Turn 9) Performance - Annual Values } \\
\hline Performance Measure & \multicolumn{2}{|c|}{ Vehicles } \\
\hline Cost & 524,962 & $\$ / \mathrm{y}$ \\
\hline Fuel Consumption & 441,008 & $\mathrm{~L} / \mathrm{y}$ \\
\hline Carbon Dioxide & $1,102,830$ & $\mathrm{~kg} / \mathrm{y}$ \\
\hline Hydrocarbons & 2,324 & $\mathrm{~kg} / \mathrm{y}$ \\
\hline Carbon Monoxide & 30,010 & $\mathrm{~kg} / \mathrm{y}$ \\
\hline NOx & 1,020 & $\mathrm{~kg} / \mathrm{y}$ \\
\hline
\end{tabular}




\section{CONCLUSION}

In the present paper, facts about the cost of congestions in one of the many congestion spots around Cairo are presented. In the present case study the congestion is resulted preliminary from adopting one of the traffic designs in an improper place (U-turn concept). Practically there are no statistical data available for the number of U-turns or sold vehicle data base. Accordingly, simulation software was utilized with different approximations to estimate the operating cost.

As demonstrated in the present paper, the cost of gasoline and other operating and maintenance requirements attributable to congestion is relatively high. The individual persons share the invoice with the government. Efforts to reduce congestion can have a positive effect on fuel consumption and consequently on air quality. Although further expansion of roads, if applicable, may provide short-term congestion relief benefits, other solutions may be adopted by the government or individuals for long term effect. However, increasing transportation supply is not sufficient to end congestion.

After all, Cairo is unlikely to be able to sustain a high level of vehicle ownership due to the high population densities which will convert the whole city to be a huge park for vehicles if the rate of selling cars is maintained at the same level. An effective strategy to reduce congestions in the Egyptians roads has to be implemented very soon.

\section{REFERENCES}

[1] The monthly AMIC report, http://www.amicegypt.com.

[2] Black A., "Urban Mass Transportation Planning", McGraw-Hill, 1995.

[3] Zhang, K., Frey, H.C., "Road grade estimation for on-road vehicle emissions modeling using light detection and ranging data", Journal of Air and Waste Management Association 56 (2006) 777-788.

[4] Chen, C., Huang, C., Jing, Q., Wang, H., Pan, H., Li, L., Zhao, J., Dai, Y., Huang, H., Schipper, L., Streets, D.G., "On-road emission characteristics of heavy-duty diesel vehicles in Shanghai", Atmospheric Environment 41 (2007) 5334-5344.

[5] Brundell-Freij, K., Ericsson, E., "Influence of street characteristics, driver category and car performance on urban driving patterns", Transportation Research Part D 10 (2005), 213-229.

[6] The Benefits of Reducing Congestion, NCHRP Project 8-36, prepared by Cambridge Systematic, Inc. for National Cooperative Highway research Program, National Research Council, 2002.

[7] Heywood, J. B. "Internal Combustion Engine Fundamentals", McGraw-Hill, 1988.

[8] El-Shawarby, I., Ahn, K., Rakha H., "Comparative field evaluation of vehicle cruise speed and acceleration level impacts on hot stabilization emissions", Transportation Research Part D 10 (2005) 13-30.

[9] Fuel Consumption Guide 2010, Natural Resources Canada (NRCan), 2010.

[10] Fenger, J., “Urban air quality", Atmosperic Environment 33 (1999) 4877-4900. 
[11] Carr, D., Von Ehrenstein, O., Weiland, S., Wagner, C., Wellie, O., Nicolai, T., Von Mutius, E., "Modeling annual benzene, toluene, NO2, and soot concentrations on the basis of road traffic characteristics", Environmental Research Section A 90 (2002) 111-118.

[12] Oduyemi, K., Davidson, B., "The impacts of road management on urban air quality", Science of the Total Environment 218 (1998) 59-66.

[13] Rapone, M., Andre', M., "Analysis and modeling of the pollutant emissions from European cars regarding the driving characteristics and test cycles", Atmospheric Environment 43 (2009) 986-995.

[14] Hallmark, S., Fomunung, I., Guensler, R., and Bachman,W., "Assessing the Impacts of Improved Signal Timing as a Transportation Control Measure Using an Activity-Specific Modeling Approach," Transportation Research Record No. 1738 (2000).

[15] Hennessy, D., and Wiesenthal, D., "Traffic Congestion, Driver Stress, and Driver Aggression," Aggressive Behavior 25 (1999).

[16] Aggressive Driver study, Florida Department of Highway Safety \& Motor Vehicles, October 1999.

[17] The Commuter's Challenge: The impact of traffic congestion in the U.S., Commuter Pain Survey, IBM Corporation September 2009.

[18] Lajunen T., Parker D., "Are aggressive people aggressive drivers? A study of the relationship between self-reported general aggressiveness", driver anger and aggressive driving. Accid Anal Prev, 33 (2001) 243-55.

[19] Parker D., Lajunen T., Summala H., "Anger and aggression among drivers in three European countries", Accid Anal Prev. 34: 229-35, 2.

[20] Roger P. Roess, Elena S. Prassas, William R. McShane, "Traffic Engineering", $3^{\text {rd }}$ edition, Peason Prentice Hall, 2004.

[21] Jha, M., Schonfeld, P., Jong, J., Kim, E., "Intelligent road design", WIT press, 2006.

[22] Harwood, D., "Median intersection design", Report / Transit Cooperative Research Program, Transportation Research Board, American Association of State Highway and Transportation Officials, National Academy Press, 1995.

[23] Potts, I., "Safety of U-turns at unsignalized median openings", National Cooperative Highway Research Program, National Research Council, Report 524, 2004.

[24] Unconventional Left-Turn Lanes Reduce Traffic Accidents, Congestion, North Carolina State University, Press release, Retrieved December 20, 2010. http://www.ci.farmington-hills.mi.us/egov/docs/1098972815_561889.pdf.

[25] Nicholes J. Garber, Laster A. Hoel, "Traffic \& Highway Engineering", 4th ed., Cngage Learning, 2009.

[26] http://www.sidrasolutions.com/

[27] Akcelik, R., Besley M., "Operating cost, fuel consumption, and emission models in aaSIDRA and aaMOTION", 25th conference of Astraline Institues of Transport Research (CAITR), 2003. 